\title{
Renal histopathological changes in a child with Laurence-Moon-Biedl syndrome
}

\author{
BONITA FALKNER, CRAIG LANGMAN, AND SHELIA KATZ \\ From the Hahnemann Medical College and Hospital, 230 North Broad Street, Philadelphia, \\ Pennsylvania 19102, USA (215) 448-7708
}

SUMMARY This report describes a case of Laurence-Moon-Biedl syndrome identified in a 24-monthold boy. Significant renal involvement was present with right-sided vesicoureteral reflux, cystocele, urinary tract infections, and growth arrest of the right kidney. After the development of hypertension a left renal biopsy was performed to determine if bilateral renal disease was present. Histopathological and ultrastructural changes in the left kidney are described. These changes appear to be unrelated to pyelonephritis or hypertension and to be most consistent with the nephropathy of Laurence-Moon-Biedl syndrome.

The complex of retinitis pigmentosa, mental retardation, obesity, hypogonadism, and polydactyly comprises the Laurence-Moon-Biedl syndrome (LMBS). Other anomalies, such as renal, skull, and liver lesions, have been included in descriptions of the syndrome but are not considered essential to the diagnosis (Nadjmi et al, 1969). Nevertheless, recent studies have indicated that there is a high incidence of associated renal anomalies, with renal failure as a major cause of early death in individuals affected with the syndrome (McLoughlin and Shanklin, 1967; Nadjmi et al., 1969; Hurley et al., 1975). The following is a report of a case of Laurence-MoonBiedl syndrome with renal involvement in a very young child. Renal histological and ultrastructural findings are described.

\section{Case history}

WM is a Spanish-American boy who was initially admitted to Hahnemann Medical College and Hospital at 4 months of age for moderate respiratory distress with wheezing. A diagnosis of acute bronchiolitis was made. The child's weight was $5400 \mathrm{~g}$ (3rd percentile). His length was $54 \mathrm{~cm}$ (50th percentile for 1 month of age) and his head circumference was $37 \mathrm{~cm}$ (50th percentile for 3 weeks of age), both of which were below the 3 rd percentile for age. He had a supranumerary digit, postaxial in position on both hands and on the left foot. The phallus was small. During the medical evaluation for his respiratory illness significant bacteriuria was documented on

Received for publication 12 April 1977 multiple cultures. The bacteriuria was coincidentally treated with the antibiotics which he received for the respiratory disease. On discharge he was referred to the paediatric renal clinic for further management of the urinary tract infection.

A second urinary tract infection was diagnosed at age $5 \frac{1}{2}$ months on the basis of two consecutive urine cultures from which grew more than 100000 colonies of coagulase negative staphylococci. The child was essentially asymptomatic. After treatment an intravenous pyelogram and voiding cystourethrogram were performed. The intravenous pyelogram demonstrated two kidneys of normal size, position, and function with adequate excretion of contrast material. The cystogram showed vesicoureteral reflux up a dilated right ureter continuous with the pelvis of the right kidney. Also demonstrated was a trigonal diverticulum of the bladder adjacent to the site of ureteral insertion. The child's height and head circumference remained below the 3rd percentile while his weight was at the 10th percentile for age. Developmental assessment indicated that landmarks were consistent with his chronological age.

At 8 months of age a third episode of asymptomatic bacteriuria due to a Proteus infection was determined on the basis of serial cultures. It is notable that at this time the child's weight was in the 50th percentile while his height and head circumference remained below the 3 rd percentile (50th percentile for 4 months of age and 17 weeks of age respectively).

Owing to the repeated episodes of bacteriuria in the presence of demonstrable right ureteral reflux and cystocele, the patient was admitted to hospital at 11 months of age and underwent surgical reimplan- 
tation of the right ureter. A postoperative cystogram showed absence of reflux bilaterally. At this time the child's weight was in the 90th percentile while his height and head circumference remained markedly below the 3rd percentile (50th percentile for 5 months of age and 22 weeks of age respectively). Additionally, there appeared to be significant delay in developmental progress, a neurological evaluation demonstrating a developmental age of 7 months.

During the subsequent year the child became markedly obese. His weight exceeded the 97th percentile while his height and head circumference remained below the 3rd percentile. The developmental delay became more apparent and he was not able to walk without support until 22 months of age.

Because of the presence of polydactyly, developmental delay, obesity, small phallus, and renal abnormalities the child was admitted to hospital at age 24 months for further evaluation. On admission his height was $86 \mathrm{~cm}$ (25th percentile) and his weight was $17.5 \mathrm{~kg}$ (greater than 97th percentile). Head circumference was $47 \mathrm{~cm}$ (3rd percentile). His blood pressure was $160 / 100 \mathrm{mmHg}$. Neurological evaluation reconfirmed his developmental retardation with a developmental age of 12 months. Skull films were normal. An electroencephalogram demonstrated a normal waking and sleeping pattern. Ophthalmological examination revealed pigmentary changes of the retina. Further laboratory studies were the following:

Urinalysis revealed an acid $\mathrm{pH}$, specific gravity was 1.018 , and protein, sugar, and acetone were absent. The urinary sediment contained 0-2 WBC, $0 \mathrm{RBC}$, and no casts/hpf. The blood glucose was $80 \mathrm{mg} / \mathrm{dl}(4.4 \mathrm{mmol} / \mathrm{l})$, serum urea $24 \mathrm{mg} / \mathrm{dl}(3.98$ $\mathrm{mmol} / \mathrm{l})$, and serum creatinine $0.5 \mathrm{mg} / \mathrm{dl}(44.2$ $\mathrm{mmol} / \mathrm{l})$. Serum electrolytes were: sodium $137 \mathrm{mEq} / 1$ (137 mmol/l), potassium $5.4 \mathrm{mEq} / 1(5.4 \mathrm{mmol} / \mathrm{l})$, chloride $105 \mathrm{mEq} / \mathrm{l},(105 \mathrm{mmol} / \mathrm{l})$, and bicarbonate $20 \mathrm{mEq} / 1 \mathrm{~m}(20 \mathrm{mmol} / \mathrm{l})$. Accurate 24-hour urine collections could not be obtained. A five-hour urine collection yielded a creatinine clearance of $28 \mathrm{ml} / \mathrm{min}$, corrected to $50 \mathrm{ml} / \mathrm{min} / 1.73 \mathrm{~m}^{2}$. This value may be falsely low due to inaccuracies in short period collections at this age. Urine sodium was $20 \mathrm{mEq} / \mathrm{l}$ $(20 \mathrm{mmol} / \mathrm{l})$, urine potassium $70 \mathrm{mEq} / 1(70 \mathrm{mmol} / \mathrm{l})$, and urine calcium $1.4 \mathrm{mg} / \mathrm{dl}(0.35 \mathrm{mmol} / \mathrm{l})$. An intravenous pyelogram demonstrated a normal size left kidney and a small contracted right kidney without evidence of hydronephrosis, consistent radiographically with the appearance of unilateral chronic pyelonephritis. Peripheral vein renin was $1.90 \times 10^{-6}$ Goldblatt units (laboratory normal: $0 \cdot 1-1.1 \times 10^{-4}$ Goldblatt units). Right renal vein renin was $2 \cdot 10 \times 10^{-6}$ Goldblatt units and left renal vein renin was $2.4 \times 10^{-6}$ Goldblatt units (laboratory normal: $1 \cdot 0-2.5 \times 10^{-4}$ Goldblatt units). Plasma cortisol was $13 \mu \mathrm{g} / \mathrm{dl}(358 \mathrm{nmol} / \mathrm{l})$ at 8 am (laboratory normal: $5-20 \mu \mathrm{g} ; 138-551 \mathrm{nmol} / \mathrm{l})$ and $4 \mu \mathrm{g} / \mathrm{d}$ $(110.4 \mathrm{nmol} / \mathrm{l})$ at $8 \mathrm{pm}$ (laboratory normal: $3-13 \mu \mathrm{g}$ (828-358 nmol/l)). Plasma testosterone was $25 \mu \mathrm{g} / \mathrm{dl}$ $(867 \mathrm{nmol} / \mathrm{l})$. After administration of 5000 units of human chorionic gonadotropin intramuscularly daily for three consecutive days plasma testosterone was $245 \mu \mathrm{g} / \mathrm{dl}(849 \mathrm{nmol} / \mathrm{l})$ which demonstrated adequate gonadal function.

The aetiology of the child's hypertension was thought to be unilateral pyelonephritis. Owing to his very young age and previous inconsistent follow-up care, consideration was given to the possibility of curing the hypertension by removing the pyelonephritic right kidney rather than relying on long-term medical management. However, in view of the other features of Laurence-Moon-Biedl syndrome and the possibility of bilateral renal disease, it was considered that the left kidney should be studied pathologically before the course of hypertensive management was determined. Accordingly, an open left renal biopsy was performed.

\section{Method}

The renal tissue obtained at biopsy was trisected. The largest portion was preserved in $10 \%$ formalin, embedded in paraffin, cut at 4 microns, and stained with haematoxylin and eosin, periodic acid Schiff, Masson's trichrome, and methenamine silver. The second portion was snap frozen in isopentane which precooled to -60 degrees Centigrade. The frozen tissue was sectioned on a cryostat at 4 microns, fixed in phosphate buffered saline and $95 \%$ ethanol, and layered with fluorescein conjugated rabbit antisera to human IgG, IgA, IgM, IgE, complement, and fibrinogen (Meloy). Fluorescein conjugated antihuman albumin was used as a control. The specimens were examined immediately with a Leitz Dialux microscope with a mercury power source. The third portion of tissue was fixed in $2.5 \%$ glutaraldehyde phosphate buffered solution. It was post-fixed in osmium tetroxide, dehydrated with increasing percentages of alcohol, and embedded in Spur media. Glomeruli were isolated and sectioned on an LKB ultratome. The sections were suspended on copper grids and stained with lead citrate and uranyl acetate. The grids containing stained tissue were examined with a Zeiss EM-9 electron microscope.

\section{Results}

The prominent histopathological lesion was diffuse glomerular fullness, produced by mild mesangial hypercellularity plus marked endothelial and visceral 


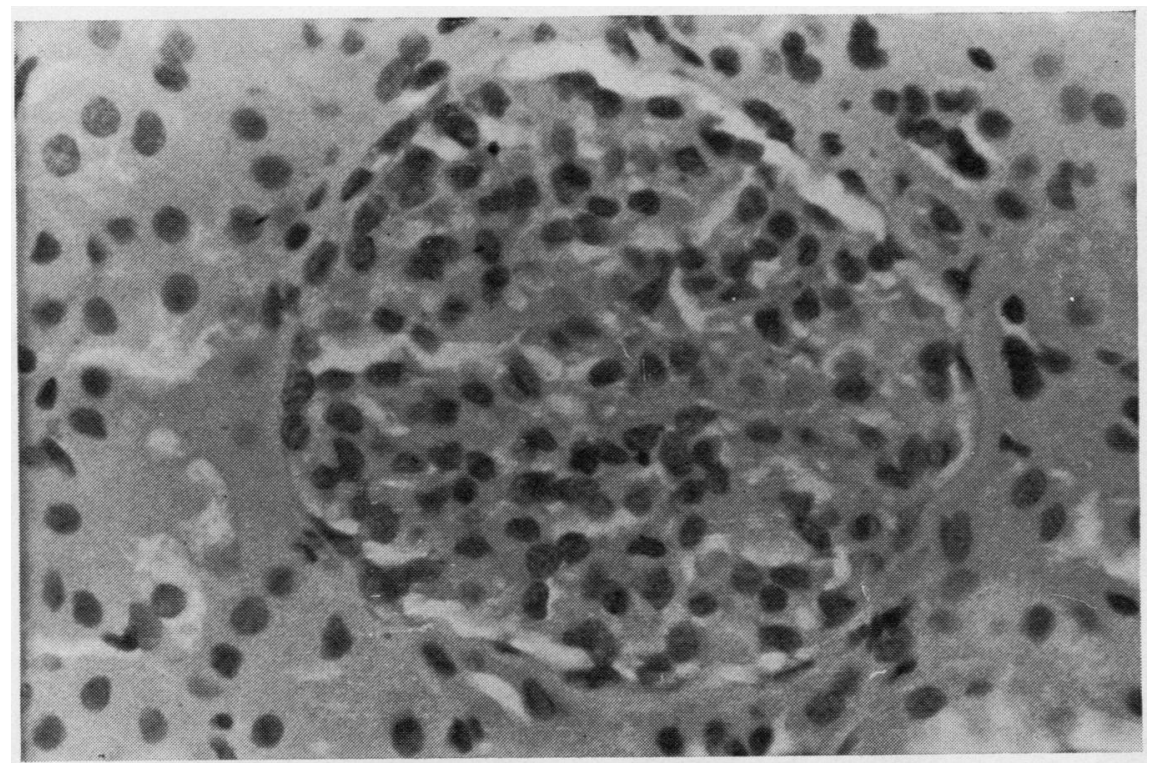

Fig. 1 A representative glomerulus from the renal biopsy sample demonstrates narrowing of capillary lumina and Bowman's space, imparting overall fullness. Endothelial and visceral epithelial cell swelling plus mesangial widening and mild mesangial hypercellularity are evident. (Haematoxylin and eosin $\times 400$ )

epithelial swelling. The swelling was associated with segmental narrowing or total obliteration of capillary lumina plus segmental narrowing of Bowman's space (Fig. 1). None of the 31 glomeruli in the sample were hyalinised and no glomerular neutrophils were seen. Roughly one-fifth of the arterioles displayed moderate mural thickening and luminal narrowing. The tubules and interstitial tissue were histologically normal, documenting an absence of pyelonephritis in the biopsy specimen. Immunofluorescent examination of an adequate renal sample was negative for tissue immunoglobulins, complement, and fibrin. Ultrastructural lesions consisted of diffuse, marked, glomerular, endothelial swelling plus segmental severe visceral epithelial swelling. These lesions were associated with diffuse capillary lumen narrowing and segmental obliteration of Bowman's space. Mild, segmental subendothelial scalloping of the glomerular basement membranes plus a mild increase in mesangial matrix was observed (Fig. 2). The adjacent tubules and interstitial tissue were ultrastructurally normal. Light, immunofluorescent, and electron microscopic findings were interpreted as indicative of non-immunological, diffuse glomerulopathy and focal moderate arteriolonephrosclerosis of the left kidney.

\section{Discussion}

Laurence-Moon-Biedl syndrome is an uncommon disorder which may be diagnosed in childhood. However, the diagnosis is rarely determined in the very young child, only a few cases having been reported in children less than 3 years of age (McLoughlin and Shanklin, 1967; Moini et al., 1975). It is interesting that this child presented in early infancy with failure to thrive and manifested the beginnings of obesity and developmental retardation only at 8 months of age. Recent reports have noted the unusually high incidence of renal and urological anomalies associated with the syndrome. Nadjmi and associates (1969) reviewed reported necropsies and found a high incidence of uraemia as a cause of death. Hurley and associates (1975) studied nine patients with LMBS, all of whom had advanced renal involvement. Of this group, five were uraemic and two were dead at ages 15 and 10 years, respectively. All nine patients had urological abnormalities demonstrated radiographically. Histopathological changes varied from mild mesangial proliferation in the mildest case to more severe mesangial proliferation and sclerosis, cystic dilatation of the tubules, cortical and medullary cysts, periglomerular and interstitial fibrosis, and chronic inflammatory cell infiltration in the more severely affected patients.

The patient described in this report had significant renal involvement associated with LMBS. Recurrent urinary tract infections associated with right-sided ureteral reflux were documented at an early age. 


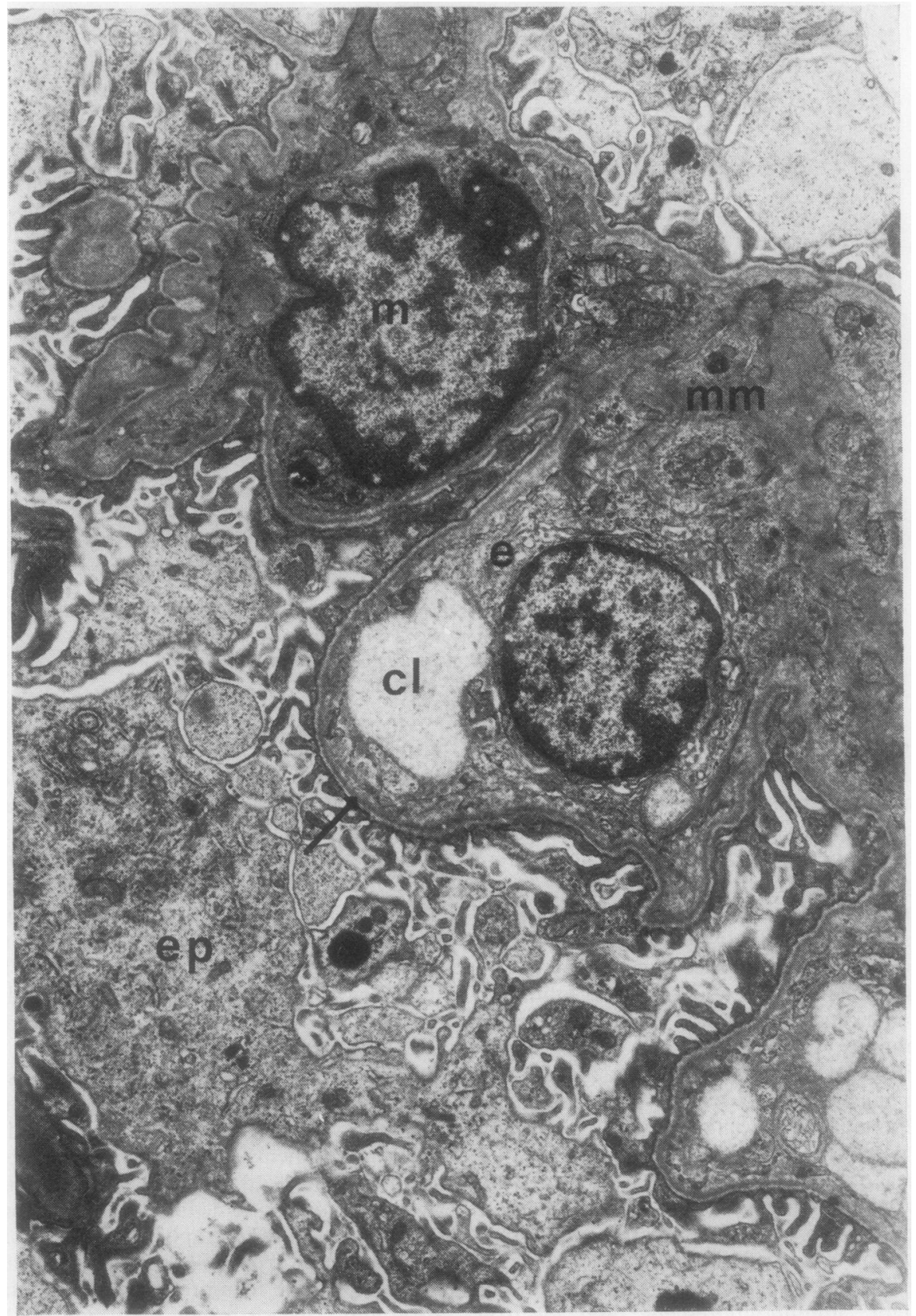

Fig. 2 A glomerular electron micrograph illustrates a markedly swollen endotheliai cell (e), a narrowed capillary lumen (cl), and a plump visceral epithelial cell (ep) with abundant cytoplasm. The glomerular basement membrane (arrow) has mild segmental scalloping involving the subendothelial side. A mesangial cell $(m)$ is normal, but there is an increase of mesangial matrix $(\mathrm{mm})$. (Lead citrate $\times 6262)$ 
Subsequent right-sided parenchymal scarring and arrested renal growth may have been the result of chronic pyelonephritis and the cause of the hypertension. However, the histological and electron microscopic changes in the left kidney are neither normal nor are they likely to be secondary to the right-sided disease. It is also unlikely that the renal pathology represents target organ damage from hypertension alone. The renal histopathological changes by light microscopy in non-malignant essential hypertension are those of mild segmental basement membrane thickening and some mesangial proliferation (McGregor, 1930; Sommers et al., 1958). The basement membrane thickening has also been demonstrated on electron microscopy (Katz et al., 1977, personal communication).

This patient, who was 24 months of age at the time of study, is one of the youngest reported cases of LMBS with renal histopathological and ultrastructural changes described. The pathological changes in this patient may not be static in nature but, as disease ensues, may well progress to a pathological state similar to that described by Hurley and associates.

Descriptions of early renal pathological and ultrastructural changes in LMBS are not available. The predominant ultrastructural change found in this case was swelling and expansion of the endothelial cells. Such a change may be seen as an injury response in such disorders as haemolytic-uraemic syndrome and irradiation nephritis (Churg and Grishman,
1975). Thus, the pathological changes described in this case appear to be real and are not related to pyelonephritis, hypertension or immune-complex disease. Therefore, it is believed that these findings represent definite changes of nephropathy in this patient with LMBS.

\section{References}

Churg, J., and Grishman, E. (1975). Ultrastructure of glomerular disease: A review. Kidney International, 7, 254-270.

Hurley, R. M., Dery, P., Nogrady, M. B., and Drummond, K. N. (1975). The renal lesion of the Laurence-MoonBiedl Syndrome. Journal of Pediatrics, 87, 206-209.

McGregor, L. (1930). Histological changes in the renal glomerulus in essential (primary) hypertension. American Journal of Pathology, 6, 347-366.

McLoughlin, T. G., and Shanklin, D. R. (1967). Pathology of Laurence-Moon-Bardet-Biedl Syndrome. Journal of Pathology and Bacteriology, 93, 65-79.

Moini, A. R., Emamy, H., and Asadian, A. (1975). The Laurence-Moon-Biedl Syndrome. Clinical Pediatrics, $14,812-815$.

Nadjmi, B., Flanagan, M. J., and Christian, J. R. (1969). Laurence-Moon-Biedl Syndrome associated with multiple genito urinary tract anomalies. American Journal of Diseases of Children, 117, 352-356.

Sommers, S. C., Relman, A. S., and Smithwick, R. H. (1958). Histologic studies of kidney biopsy specimens from patients with hypertension. American Journal of Pathology, 34, 685-716. 